\title{
Adsorption Study on DR28 Dye by Subabul Timber Waste Using Taguchi's Laboratory Test
}

${ }^{* 1}$ Tripti B. Gupta, ${ }^{2}$ Khalid S. Ansari

${ }^{*}$ Shri Ramdeobaba College of Engineering and Management, Nagpur

${ }^{2}$ Yeshwantrao Chavan College of Engineering, Nagpur

Email: ${ }^{1}$ guptatb@rknec.edu, ${ }^{2}$ khalidshamim86@rediffmail.com

Received: 22nd October 2019, Accepted: 20th November 2019, Published: 31st December 2019

\begin{abstract}
Here in current work, Taguchi's laboratory test method for optimizing processing parameters have been considered to discuss most favorable level of adsorption for the removal of DR28dye using Subabul timber waste. The outcome of personage processing parameters, viz. Subabul timber waste dose, DR28dye concentration, adsorption temperature and period of contact on the chosen responsive features have been studied. The mean values and Signal/Noise ratio of the responsive parameters for separate characteristic at 3 personage levels have been anticipated using $\mathrm{L}_{9}$ orthogone matrix. For the diagrammatic depiction of the variation in assessment of responsive parameters and that of Signal/Noise ratio with the distinction in processing parameters, the responsive graphs have been drawn. These responsive graphs have been considered for investigating processing parameter outcomes on the responsive parameters. The variance analysis for virgin record and Signal/Noise record has been carried out so as to make out the noteworthy parameters and to quantify their outcomes on the responsive parameters. The most encouraging optimum situation in requisites of mean responsive parameters of characters has been recognized by investigating responsive graphs and the analysis of matrices. The most favorable levels of parameters for DR28dye were found to be $a_{1}, b_{3}, c_{3}$ and $d_{3}$. The pre-estimated and validated confirm values of DR28dye absorbed on Subabul timber waste at optimum settings were found to be $1.53 \mathrm{mg} / \mathrm{g}$ and $1.55 \mathrm{mg} / \mathrm{g}$ respectively.
\end{abstract}

\section{Keywords}

DR28 Dye, Orthogone Matrix, Subabul Timber Waste, Variance Analysis

\section{Introduction}

Each creature in the universe should be concerned about environment, of mother-nature and of water $\left(\mathrm{H}_{2} \mathrm{O}\right)$. So wasting unnecessary water or using excess than required water should have some concern of worry, some concern of accountability and with that some concern of regulation [1]. These days, environmental litter mainly water pollution and soil pollution is one among the chief issues. The organic litters and inorganic litters, toxic elements not only get in touch with the surface sources like sea, lake, and pond but can also pollute sub-surface sources in majorly through leaching action. Therefore, the surface and the sub-surface sources may include different lethal toxicants. We must do treatment of this water before its release or dumping, as it is the main endanger resource in the sphere. Adsorption is one of the most effective methods amongst all the treatment methods. This system turns out to be additional profitable if the adsorbent considered is economical. Here in current work, adsorption investigation on DR28dye by Subabul timber waste using experiments by Taguchi's method is been conceded. Adsorbent is a plant matter produced from a nearby mounting commonly found tree which is with no trouble accessible as an adsorbent and can be worn for the deduction of dye from waste.

\section{Laboratory Tests Method}

The Taguchi's method is an optimization procedure to classify every probable setting in a test concerning numerous factors. Here laboratory tests are conducted by means of particularly established matrices known as orthogone matrix (OM). To draw laboratory tests, one has to choose the appropriate OM [2]. In the method, line plots and triangle columns are used. This builds the parameters obligation easy. In this technique, the outcomes of the laboratory tests are analyzed to accomplish different objectives as follows:

i) To set up the top or the most favorable setting so as to get the entire up-take of DR28dye by adsorption on Subabul timber waste in matrices having diverse sets.

ii) To predict the involvement of personage parameters on the optimal sorption uptake of DR28dye and to validate the responsive optimal settings.

The optimal settings are recognized by understanding the main outcomes of every parameter. The main outcome reflects the universal style of control of every para-meter on the processing. The information of involvement of personage parameters is important in finalizing the character of control to be recognized. The variance analysis (VA) is considered to the laboratory tests outcomes in deciding the \% share in the form of contribution of every para-meter in opposition to a affirmed level of confidence (LOC). The control of parameters can be decided by understanding VA for a known study.

There are 2 diverse ways to clutch out the entire study. In the regular way, the outcomes of a solo run or the mean of repeat runs are followed through chief outcome and through VA. In the subsequent way, numerous runs are taken and the signal by noise ratio for the similar steps is considered. The signal by noise ratio is a synchronized quality connected to the functional loss (LF) [3], and by maximizing the signal by noise ratio, the related loss can be decreased. The signal by noise ratio decides the main robust unit of working situations from discrepancy within the outcomes. The signal by noise ratio is considered as a response of the laboratory tests. The external $\mathrm{OM}$ is considered to power the noise deviation into the test. On the other hand, processes are frequently 
dependent on different noise factors that in amalgamation powerfully sway the deviation of the responsiveness. For tremendously noised sets, it is not normally essential to classify precise noise factors and to consciously control them throughout laboratory tests. It is adequate to produce repeats at every test situations and study them by considering a suitable signal by noise ratio [4]. In the current search, both the studies: the virgin data study and the signal by noise data study have been conceded. The outcomes of the chosen parameters on the chosen quality features, total DR28dye adsorbed in mg on the Subabul timber waste per g of Subabul timber waste have been analyzed through the graphs of the chief outcomes dependent on the virgin data. The optimal settings for the quality features have been recognized through signal by noise ratio data studies along with virgin data studies. No external OM has been considered. In spite of it, laboratory tests have been repeated thrice at every test conditions.

\section{Steps in Laboratory Tests}

Assortment of OM: In Assortment of suitable OM, the basics are: (i) Assortment of processing parameters to be examines, and (ii) Assortment of number of levels for the important parameters [1]

Para-meter design approach: When the VA on the virgin data and signal by noise ratio data are accomplished, the control parameters may be place into following 4 modules [5]:

Module (1) Para-meter influencing together average and variation

Module (2) Para-meter influencing just variation

Module (3) Para-meter influencing just average

Module (4) Para-meter influencing not anything

\section{Analysis of L9 OM}

This array has been used for the carrying out tests in single and binary sorption sets. The tests in every trial have been repeated 3 times. Thus, three responses for every trial have been noted. These responses are indicated by $y_{i j}, i=1,2, \ldots \ldots, 9$, and $j=1,2,3$ and are shown in the response column under $\operatorname{Run}_{1}, \mathrm{Run}_{2}$ and $\mathrm{Run}_{3}$ The signal by noise ratio are represented by $\mathrm{s} / \mathrm{n}, i=1,2, \ldots, 9$. Since 9 laboratory tests are specified in the $\mathrm{L}_{9} \mathrm{OM}$, so there are a total of 27 and $(=3 \times 9)$ responses and 9 signal by noise ratios [6]. The signal by noise ratio decides the main robust unit among working conditions from deviation inside the outcomes.

\section{Results and Discussions}

Taguchi's Laboratory Test Method:

The critical parameters affecting the adsorptive removal of DR28dye using Subabul timber waste, the array of standards along with their levels are shown in Table 1. As shown in Table 1, 4 different parameters, all at 3 levels were used in the $\mathrm{L}_{9} \mathrm{OM}$ and the 9 laboratory test were conceded in triple runs beneath the similar situation as given in Table 2 . The \% removal of DR28dye by Subabul timber waste is given in Table 3 and Table 4. $\mathrm{L}_{9} \mathrm{OM}$ is the optimal method to run only 9 laboratory test in diverse sets of parameters at 3 levels.

\begin{tabular}{|c|c|c|c|c|c|}
\hline \multirow{2}{*}{ Feature } & \multirow{2}{*}{ Parametric factor } & \multirow{2}{*}{ Unit } & \multicolumn{3}{|c|}{ Parametric Level } \\
\cline { 4 - 6 } & & & \multicolumn{3}{|c|}{ Subabul Timber Waste } \\
\cline { 4 - 6 } & & & I & II & 3.5 \\
\hline $\mathrm{a}$ & Subabul timber waste dose & $\mathrm{gm} / \mathrm{lt}$ & 1.5 & 2.5 & 150 \\
\hline $\mathrm{b}$ & DR28dye concentration & $\mathrm{mg} / \mathrm{lt}$ & 50 & 100 & 40 \\
\hline $\mathrm{c}$ & Adsorption temperature & ${ }^{\circ} \mathrm{C}$ & 20 & 30 & 5 \\
\hline $\mathrm{d}$ & Period of contact & $\mathrm{Hr}$ & 1 & 3 & 5 \\
\hline
\end{tabular}

Table 1: Processing Parameters for Removal of DR28dye by Subabul Timber Waste Using OM (L9).

\begin{tabular}{|c|c|c|c|c|c|}
\hline \multirow{2}{*}{ Test order } & \multirow{3}{*}{ Run } & \multicolumn{5}{|c|}{ Parametric factor } \\
\cline { 3 - 6 } & & $\mathbf{a}$ & $\mathbf{b}$ & $\mathbf{c}$ & $\mathbf{d}$ \\
\hline 6 & 1 & 2 & 3 & 1 & 2 \\
\hline 5 & 2 & 2 & 2 & 3 & 1 \\
\hline 7 & 3 & 3 & 1 & 3 & 2 \\
\hline 2 & 4 & 1 & 2 & 1 & 3 \\
\hline 8 & 5 & 3 & 2 & 2 & 1 \\
\hline 9 & 6 & 3 & 3 & 3 & 3 \\
\hline 3 & 7 & 1 & 3 & 2 & 3 \\
\hline 4 & 8 & 2 & 1 & 1 & 1 \\
\hline 1 & 9 & 1 & 1 & & \\
\hline
\end{tabular}

Table 2: Run Allocation for Different Parametric Factors in the OM. 


\begin{tabular}{|c|c|c|c|c|}
\hline No. & \multicolumn{4}{|c|}{ Final Entire Uptake, (mg/g) } \\
\hline & Run $_{1}$ & Run $_{2}$ & Run $_{3}$ & $\begin{array}{c}\text { Signal by noise ratio } \\
\text { (decibels) }\end{array}$ \\
\hline 1 & 1.520 & 1.307 & 1.347 & 2.81 \\
\hline 2 & 0.893 & 0.927 & 0.947 & -0.71 \\
\hline 3 & 0.224 & 0.195 & 0.229 & -13.38 \\
\hline 4 & 1.744 & 1.622 & 1.689 & 4.52 \\
\hline 5 & 0.767 & 0.829 & 0.748 & -2.17 \\
\hline 6 & 1.314 & 1.262 & 1.305 & 2.23 \\
\hline 7 & 2.756 & 2.644 & 2.622 & -54 \\
\hline 8 & 0.387 & 0.347 & 0.300 & -9.40 \\
\hline 9 & 0.533 & 0.656 & 0.467 & -5.41 \\
\hline
\end{tabular}

Table 3: Laboratory Tests Values for Adsorption of DR28dye onto Subabul Timber Waste Using OM

\section{Study of Laboratory Tests Data}

The Maximum-is-best quality feature was used in the study of laboratory tests data [7]. The graphs of responsive plots, VA for virgin data and $\mathrm{s} / \mathrm{n}$ ratios data were considered for the study and analysis of outcomes and to estiamte the adsorption mechanism along with its performance. The mean of the responsive feature at the optimum situation was anticipated.

\section{Outcome of Processing Parameters}

Table 4 shows the virgin data for the mean values of removal and $\mathrm{s} / \mathrm{n}$ ratio for every parameter at levels I, II, and III for adsorption of DR28dye onto Subabul timber waste. The outcome of diverse parameters viz. DR28dye concentration, Subabul timber waste dose, adsorption temperature, and period of contact from Figure 1 for the removal of DR28dye by Subabul timber waste shows that, the adsorbent dose, $\mathrm{m}$ (parameter a) at level I, DR28dye concentration (parameter b), at level III, adsorption temperature (parameter c) at level III, and period of contact time (parameter d) at level III have highest influence on \% removal of DR28dye onto Subabul timber waste. The variation flanked by influence at level II and level I ( $\left.\mathrm{L}_{\mathrm{II}}-\mathrm{L}_{\mathrm{I}}\right)$ of every parameter describes that DR28dye concentration (parameter b) has the largest influence on \% removal in assessment to supplementary parameters (Table 4 and 5).

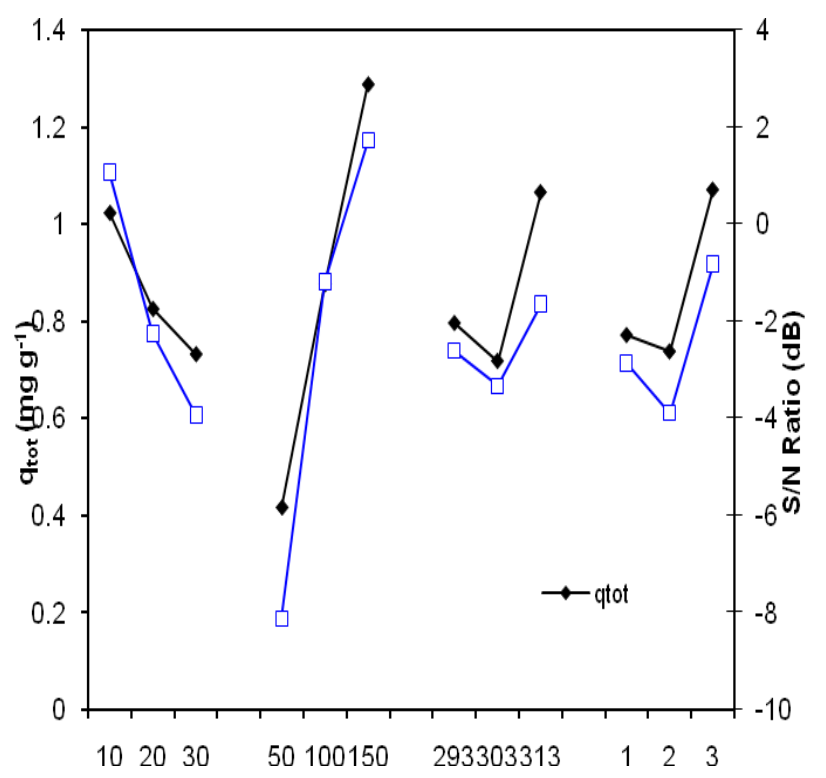

Fig 1: Outcome of Processing Parameters on \% Removal \& S/N Ratio of DR28dye onto Subabul Timber Waste 


\begin{tabular}{|c|c|c|c|c|c|c|c|c|c|c|}
\hline \multirow{2}{*}{ Features } & \multicolumn{3}{|c|}{$\begin{array}{c}\text { Virgin data } \\
\text { (Mean value) }\end{array}$} & \multicolumn{2}{c|}{$\begin{array}{c}\text { Chief outcomes } \\
\text { (Virgin data) }\end{array}$} & \multicolumn{3}{c|}{$\begin{array}{c}\text { s/n data } \\
\text { (Mean data) }\end{array}$} & \multicolumn{2}{c|}{$\begin{array}{c}\text { Chief outcomes } \\
\text { (s/n data) }\end{array}$} \\
\cline { 2 - 20 } & $\mathrm{L}_{\mathrm{I}}$ & $\mathrm{L}_{\mathrm{II}}$ & $\mathrm{L}_{\mathrm{III}}$ & $\mathrm{L}_{\mathrm{II}}-\mathrm{L}_{\mathrm{I}}$ & $\mathrm{L}_{\mathrm{III}}-\mathrm{L}_{\mathrm{II}}$ & $\mathrm{L}_{\mathrm{I}}$ & $\mathrm{L}_{\mathrm{II}}$ & $\mathrm{L}_{\mathrm{III}}$ & $\mathrm{L}_{\mathrm{II}}-\mathrm{L}_{\mathrm{I}}$ & $\mathrm{L}_{\mathrm{III}}-\mathrm{L}_{\mathrm{II}}$ \\
\hline $\mathrm{a}$ & 1.0 & 0.8 & 0.7 & -0.20 & -0.1 & 1.0 & -2.26 & -3.9 & -3.33 & -1.6 \\
\hline $\mathrm{b}$ & 0.4 & 0.8 & 1.2 & 0.46 & 0.4 & -8.1 & -1.19 & 1.7 & 6.94 & 2.9 \\
\hline $\mathrm{c}$ & 0.8 & 0.7 & 1.0 & -0.08 & 0.3 & -2.6 & -3.34 & -1.6 & -0.72 & 1.6 \\
\hline $\mathrm{d}$ & 0.7 & 0.7 & 1.0 & -0.03 & 0.3 & -2.8 & -3.90 & -0.8 & -1.02 & 3.0 \\
\hline
\end{tabular}

Table 4: Mean and Chief Outcomes of \% Removal Values for Virgin and S/N Data of DR28dye onto Subabul Timber Waste

\begin{tabular}{|c|c|c|c|c|c|c|c|c|c|c|}
\hline \multirow[t]{2}{*}{ Adsorbent } & \multicolumn{3}{|c|}{$\begin{array}{c}\text { Virgin data } \\
\text { (Mean value) }\end{array}$} & \multicolumn{2}{|c|}{$\begin{array}{c}\text { Chief outcomes } \\
\text { (Virgin data) }\end{array}$} & \multicolumn{3}{|c|}{$\begin{array}{c}\text { s/n data } \\
\text { (Mean data) }\end{array}$} & \multicolumn{2}{|c|}{$\begin{array}{c}\text { Chief outcomes } \\
\text { (s/n data) }\end{array}$} \\
\hline & $\mathrm{L}_{\mathrm{I}}$ & $\mathrm{L}_{\mathrm{II}}$ & LIII & $\mathrm{L}_{\mathrm{II}}-\mathrm{L}_{\mathrm{I}}$ & $\mathrm{L}_{\text {III- }}-\mathrm{L}_{\mathrm{II}}$ & $\mathrm{L}_{\mathrm{I}}$ & $\mathrm{L}_{\text {II }}$ & LIII & $\mathrm{L}_{\mathrm{II}}-\mathrm{L}_{\mathrm{I}}$ & $\mathrm{L}_{\text {III }}-\mathrm{L}_{\mathrm{II}}$ \\
\hline $\begin{array}{l}\text { Subabul timber } \\
\text { waste }\end{array}$ & a & $\mathrm{b}$ & $\mathrm{b}$ & $\mathrm{b}$ & $\mathrm{b}$ & a & d & $\mathrm{b}$ & $\mathrm{b}$ & d \\
\hline \multicolumn{6}{|c|}{ Features } & & & & & \\
\hline a & \multicolumn{5}{|c|}{ Subabul timber waste dose } & & & & & \\
\hline $\mathrm{b}$ & \multicolumn{5}{|c|}{ DR28dye concentration } & & & & & \\
\hline $\mathrm{c}$ & \multicolumn{5}{|c|}{ Adsorption temperature } & & & & & \\
\hline d & \multicolumn{5}{|c|}{ Period of contact } & & & & & \\
\hline
\end{tabular}

Table 5: Outline of Parameters having Maximum Influence on \% Removal of DR28dye onto Subabul Timber Waste

The involvement of the personage parameters is slanted to force control on adsorptive removal of DR28dye onto Subabul timber waste. The VA outcomes for virgin and $\mathrm{s} / \mathrm{n}$ ratio data with desired responsive features (\% removal) are shown in Table 5 for adsorption of DR28dye onto Subabul Timber Waste. The results obtained from VA for virgin and signal by noise ratio data shows that all parameters and interactions of the 3 levels are statistically significant at $95 \%$ level of confidence (LOC) for q $\mathrm{q}_{\text {tot }}$ as desired responsive feature $[8,9]$.

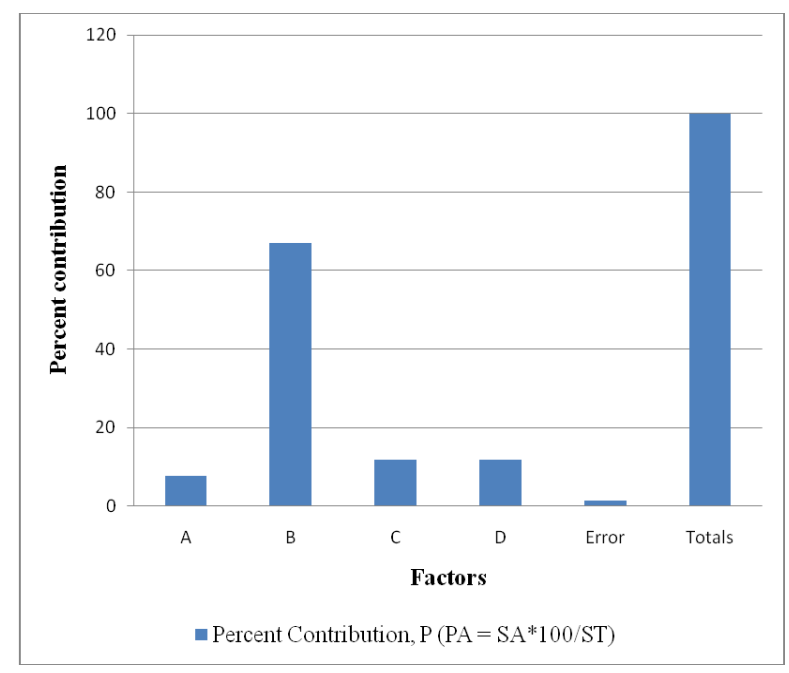

Fig 2: Involvement of Different Features for the Removal of DR28dye onto Subabul Timber Waste (\% Contribution) 


\section{Estimation of Optimum Levels and Evaluation of Optimal Responsive Features}

Considering \% removal as the Maximum-is-best quality feature, the optimal level of diverse parameters produced after investigating the responsive plots of the mean value of $\%$ removal and $\mathrm{s} / \mathrm{n}$ ratios it is observed that the level I of para-meter a, level III of para-meter b, level III of parameter $c$ and level III of parameter d results in maximum average value of \% removal for Subabul timber waste. Since the intention of the search is to remove maximum amount of DR28dye using Subabul timber waste. The important processing parameters affecting the removal of DR28dye by Subabul timber waste and their optimal levels are: $a_{1}, b_{3}$, $c_{3}$ and $d_{3}$. From Table 6 , predicted optimal values, confidence intervals (LOC) and results of confirmation experiments for adsorption of DR28dye from wastewater onto Subabul timber waste are almost same as optimum. [10].

\begin{tabular}{|c|c|c|c|c|}
\hline Adsorbent & Optimum levels & $\begin{array}{c}\text { Estimated } \\
\text { values }\end{array}$ & $95 \%$ LOC & $\begin{array}{c}\text { Average of confirmation } \\
\text { tests }\end{array}$ \\
\hline $\begin{array}{c}\text { Subabul timber } \\
\text { waste }\end{array}$ & $\mathrm{a}_{1} \mathrm{~b}_{3} \mathrm{c}_{3} \mathrm{~d}_{3}$ & 1.53 & $\mathrm{LOC}_{\mathrm{POP}}: 1.31<\mu<1.76$ & \multirow{2}{*}{1.55} \\
\cline { 3 - 4 } & & $\mathrm{LOC}_{\mathrm{CE}}: 1.30<\mu<1.77$ & \\
\hline
\end{tabular}

Table 6: Estimated Values, LOC and Outcome of Confirmation Tests for Adsorption of DR28dye using Subabul Timber Waste

\section{Conclusions}

From the current study, it is found that study on Taguchi's laboratory test on adsorption and optimization of DR28dye by Subabul timber waste could be very reasonable from sources, time savings and economics considerations. The 81 sets of laboratory test are deducted to just 9 sets of laboratory test. The important parameters for sorption such as Subabul timber waste dose, DR28dye concentration, adsorption temperature and period of contact at diverse levels are synchronized in merely 9 sets of trials. It is observed that maximum amount of adsorption is found to be Subabul timber waste dose at level 1, DR28dye concentration at level 3 , adsorption temperature at level 3 and period of contact at level 3 . The optimized parameters at different levels were found to be $a_{1}, b_{3}, c_{3}$ and $d_{3}$. The estimated and average of confirmation tests outcomes of DR28dye adsorbed on Subabul timber waste at optimum levels were found to be 1.53 and $1.55 \mathrm{mg} / \mathrm{g}$ respectively. Both the standards for DR28dye lie in the range of $95 \%$ LOC. It clearly shows the effectiveness of Taguchi's laboratory test method for optimization of DR28dye onto Subabul timber waste.

Acknowledgment

Dr. D. H. Lataye, Civil Engineering Department, VNIT, Nagpur

Dr. (Mrs.) M. V. Latkar, Associate Professor, Civil Engineering, VNIT, Nagpur

\section{References}

[1] Ross, P.J. 1988. Taguchi Techniques for Quality Engineering. 2nd Edn. McGraw Hill, New York, 50-59.

[2] Ross, P.J. 1996. Taguchi techniques for quality Engineering. 2nd Edn. McGraw Hill, New York, 102-179.

[3] Barker,T.B. 1990. Engineering quality by design. $1^{\text {st }}$ Edn. Marcel Dekker, New York, 21-35.

[4] Byrne, D., and Taguchi, S. 1987. The Taguchi approach to parameter design. Quality Progress 20(12): 19-26.

[5] Roy, R. 2001. Design of experiments using the Taguchi approach: 16 steps to product and process improvement. John Wiley and Sons, New York, 110-136.

[6] Gupta, T.B, and Lataye, D.H. 2017. Adsorption of indigo carmine dye onto acacia nilotica (babool) sawdust activated carbon. J. Hazard. Toxic Radioact. Waste, 21(4): 1-11.

[7] Gupta, T.B., and Lataye, D.H. Removal of crystal violet and methylene blue dyes using activated carbon of acacia nilotica sawdust. Ind.J. of Chem. Tech, 26: 52-68.

[8] Lataye, D.H., Mishra, I.M., and Mall, I.D. 2006. Removal of pyridine from aqueous solution by adsorption on bagasse fly ash. Ind. Eng. Chem. Res., 45(11), 3934-3943.

[9] Gupta, T.B., and Lataye, D.H. 2018. Adsorption of indigo carmine and methylene blue dye: Taguchi's design of experiment to optimize removal efficienc. Sadhana, Indian Academy of Sciences, 43(170):1-13.

[10] Taguchi, G., and Wu, Y. 1979. Introduction to the off-line quality control. Central Japan Quality Control Association Nagaya, Japan, 36-97. 